\title{
Metallocavitins as Promising Industrial Catalysts: Recent Advances
}

\section{Albert A. Shteinman* \\ Department of Kinetics and Catalysis, Institute of Problems of Chemical Physics, RAN, Chernogolovka, Russia}

The energy, material, and environmental problems of society require clean materials and impose an urgent need to develop effective chemical processes for obtaining and converting energy to ensure further sustainable development. To solve these challenges, it is necessary, first of all, to learn solar energy harvesting through the development of artificial photosynthesis. In our planet, water, carbon dioxide, and methane are such affordable and inexhaustible clean materials. Electro/photocatalytic water splitting, and also $\mathrm{CO}_{2}$ and $\mathrm{CH}_{4}$ transforming into valuable products, requires the search for relevant efficient and selective processes and catalysts. Of great interest is the emerging new generation of bioinspired catalysts - metallocavitins (MCs). MCs are attracting increasing attention of researchers as advanced models of metalloenzymes, whose efficiency and selectivity are well known. The primary field of MC application is fine organic synthesis and enantioselective catalysis. On the other hand, MCs demonstrate high activity for energy challenging reactions involving small gas molecules and high selectivity for converting them into valuable products. This mini-review will highlight some recent advances in the synthesis of organic substances using MCs, but its main focus will be on the rapid development of advanced catalysts for the activation of small molecules, such as $\mathrm{H}_{2} \mathrm{O}, \mathrm{CO}_{2}$, and $\mathrm{CH}_{4}$, and the prospects for creating related technological processes in the future.

Keywords: metallocavitins, sustainable developing, $\mathrm{H}_{2} \mathrm{O}, \mathrm{CO}_{2}$, methane

\section{INTRODUCTION}

In recent decades, we have witnessed the emergence of an innovative generation of bioinspired catalysts-metallocavitins (MCs). Cavitins are a class of nanoporous molecules and supramolecular ensembles interesting for heterogenous metal catalysis, based usually on transition metals. The performance of the transition metal catalyst increases due to its retention in molecular nanocontainers with intrinsic porosity usually used for preparation of metallocavitins. At the same time, microporous compounds, such as charcoal or zeolites, are used long time as carriers for metal ions in industrial heterogenous catalysis because they greatly increase the performance of the encapsulated transition metals. There are two big classes of cavitins: the first one, discrete individual molecules-monocavitins, such as, for example, cyclodextrins, calixarenes, metal-organic cages (MOCs), covalent organic cages (COCs), and, the second, extended ones- polycavitins, such as zeolites, metal-organic frameworks (MOFs), covalent organic frameworks (COFs), and polypeptides, which all together demonstrate a rich library of architectures varying in shape, size, and geometry (Figure 1). MOFs and MOCs are formed by coordination-driven self-assembly. They are composed of polydentate organic linkers and inorganic nodes containing metal ions or clusters known as secondary binding units (SBUs). On the other hand, COFs and COCs are organic molecules of different sizes and complexity, synthesized via covalent binding. M-cavitins demonstrate high activities for energetically challenging reactions with participation of small gas molecules and high selectivity to valuable 


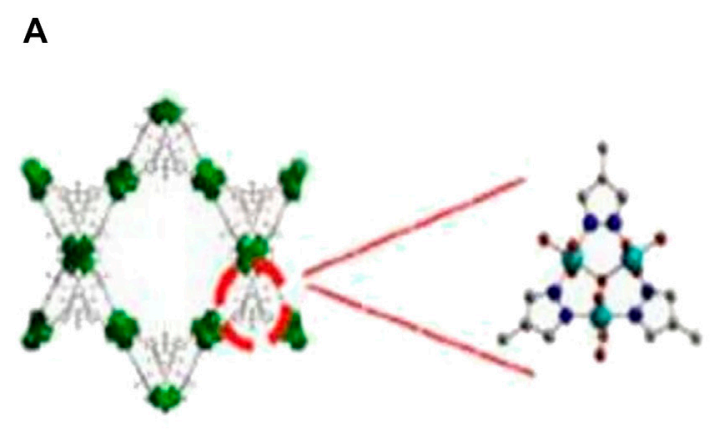

C

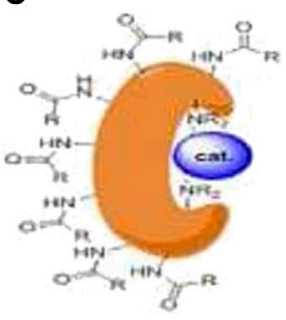

B

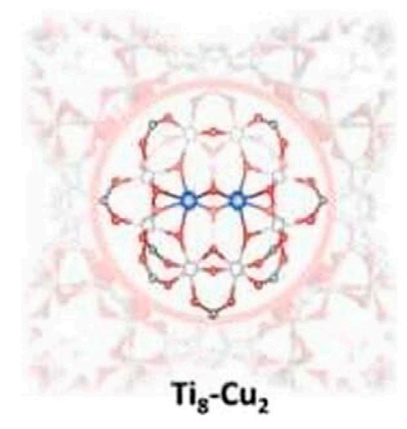

$\mathbf{E}$

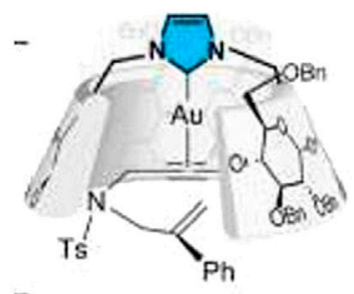

$\mathbf{F}$
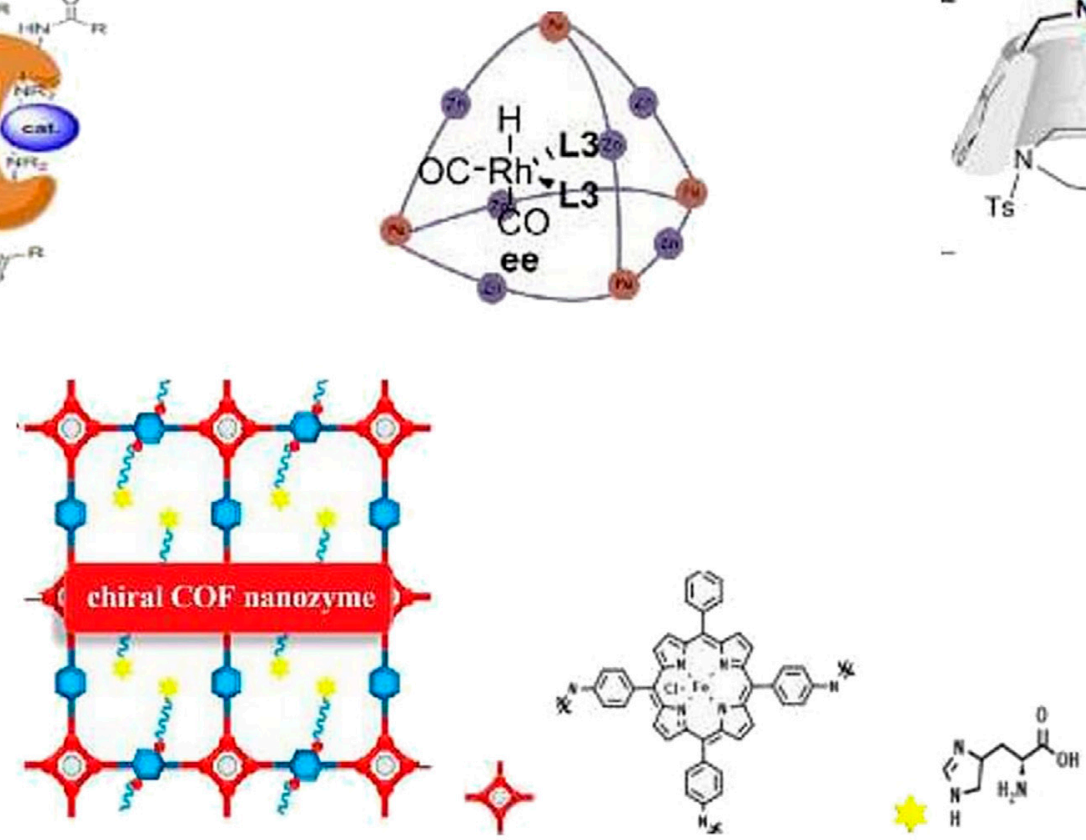

FIGURE 1 | IMC as bioinspired catalysts: (A) Artificial catechol oxidase (Li et al, 2020). (B) Artificial binuclear copper monooxygenase based on Ti-MOF (Feng et al, 2021). (C) MC (cat-RuOs) for enantioselective dihydroxylation and epoxydation of styrene derivatives (Leurs et al, 2018). (D) MC for the alkene size-selective hydroformylation (Nurttila et al, 2019). (E) N-heterocyclic carbene-capped CD-Au complex for an enantioselective enyne cycloisomerization (Roland et al., 2018). (F) Chiral COF nanozyme for enantioselective L-DOPA oxidation (Zhou et al, 2020).

products. Nowadays, the use of new sources of clean materials and the development of efficient processes for their conversion are a necessary requirement for growing energy needs and environmental protection. In this connection, M-cavitins are promising catalysts for future technology.

\section{METALLOCAVITINS AS BIOINSPIRED CATALYSTS}

Metals in the coordination cavitins may serve either only for constructive goals or also as a coordinately unsaturated catalytic center. The general approaches for the incorporation of metal active sites into cavitins include metallolinkers, non-covalent encapsulation of metal complexes and enzymes, templated metal/ligand assemblies, and post-synthetic metalation (Leenders et al., 2015). The complexity of MOCs and COCs has increased dramatically in recent times: heteroleptic, mixedmetal, and low symmetry assemblies and different composites are becoming more commonplace (Pullen et al., 2021). The right balance between flexibility and rigidity of cavitins is favorable for binding substrates and releasing products (Zhang et al., 2017). Shape-persistent organic cages permit precise control of their size and geometry (Holsten et al., 2021). On the other hand, adaptability is a hallmark of enzymes. Flexible cavitins mimic these owing to structural changes that accompany adsorption and desorption steps (Heerden et al., 2021). Cavitins are able to create chiral molecular catalysts via preferential secondary interactions between the substrate and framework that induce enantioselectivities not achievable in homogenous systems. 
TABLE 1 | Some examples of MC catalysis of organic reactions.

\begin{tabular}{|c|c|c|c|c|c|c|c|}
\hline \multirow[t]{2}{*}{ Number } & \multirow[t]{2}{*}{ Reaction } & \multirow[t]{2}{*}{ MC } & \multirow[t]{2}{*}{ Yield, \% } & \multicolumn{2}{|c|}{ Characteristics } & \multirow[t]{2}{*}{ Figure } & \multirow[t]{2}{*}{ Reference } \\
\hline & & & & TON & Selectivity, \% & & \\
\hline 1 & Catechol oxidation & $\mathrm{Cu}_{3} \mathrm{MOF}-818$ & 98 & High substrate & te specifity & $1 \mathrm{~A}$ & Li et al. (2020) \\
\hline \multirow[t]{3}{*}{2} & Epoxydation & $\mathrm{Cu}_{2} \mathrm{MIL}-125-\mathrm{Ti}$ & 84-92 & $420-3450$ & & $1 B$ & Feng et al. (2021) \\
\hline & hydroxylation & & $46-94$ & $92-480$ & & & \\
\hline & sulfoxidation & & 95 & 475 & & & \\
\hline 3 & Epoxydation & M-BSA,(M=Ru,Os) & 78 & $1613-2500$ & $82(\mathrm{~S})$ & $1 \mathrm{C}$ & Leurs et al. (2018) \\
\hline 4 & Alkene hydroformylation & $\mathrm{RhHL}_{5} @ \mathrm{Fe}_{4}(\mathrm{ZnL})_{6}$ & 33 & 800 & 99.5 & 1D & Nurttilla et al. (2019) \\
\hline 5 & Enyne cycloisomerization & AulCD & 99 & & $80(+)$ & $1 E$ & Roland et al. (2018) \\
\hline
\end{tabular}

Thus, they catalyze the asymmetric acetylation of aromatic aldehydes and 2-aminobenzamide to generate the products with up to $93 \%$ yield and $97 \%$ ee (Hou et al., 2021). As was noted, the primary field of MC application is fine organic synthesis and enantioselective catalysis. It is well-known that special channels in enzymes facilitate transport of substrates and products. The mesoporous $\mathrm{MOF} \mathrm{MnO}_{2} @ \mathrm{OMUiO}-66(\mathrm{Ce})$, containing artificial substrate channels and $\mathrm{MnO}_{2}$ attached to $\mathrm{Ce}-\mathrm{O}$ clusters, was designed as a super-active artificial catalase (Yang et al., 2021a). These authors proposed some guides for the rational design of super-active biomimetic systems. MOF-818, containing nodes of trinuclear copper centers that mimic the active sites of catechol oxidase, shows efficient catechol oxidase activity. This artificial enzyme oxidizes o-diphenoles to o-qunones with good substrate specificity ( $\mathrm{Li}$ et al., 2020, Table 1.1, Figure 1A). The direct selective oxidations of the most difficult $\mathrm{C}-\mathrm{H}$ bonds with $\mathrm{O}_{2}$ are very challenging reactions and play an important role in fine organic synthesis (Shteinman and Mitra, 2021). Nature has created highly active and selective binuclear metal-containing monooxygenases working with the participation of $\mathrm{O}_{2}$ and a reducing agent and capable of activating the most inert $\mathrm{C}-\mathrm{H}$ bond of alkanes involving methane. Recently the MOF-based artificial binuclear monooxygenase $\mathrm{Ti}_{8}-\mathrm{Cu}_{2}$ (Table 1.2, Figure 1B) was prepared via metalation of the $\mathrm{SBU}$ in a Ti-MOF. The SBU provided a precise binding pocket for the installation of binuclear $\mathrm{Cu}$ cofactors to cooperatively activate $\mathrm{O}_{2}$. In the presence of co-reductants, $\mathrm{Ti}_{8}-\mathrm{Cu}_{2}$ demonstrated excellent catalytic activity and selectivity in monooxygenation processes, including epoxidation, hydroxylation, and sulfoxidation, with TOF, which is much higher than that of mononuclear $\mathrm{Ti}_{8}-\mathrm{Cu}_{1}$ (Feng et al., 2021). It would be interesting to check and develop this monooxygenase for alkane hydroxylation involving methane. While polycavitins are used for fabrication of advanced heterogenous catalysts (Bavykina et al., 2020), monocavitins are more suitable for modeling and academic study of the enzyme active sites. However in the recent years, MOC use in catalysis has also increased. For example, the highest activity for the enantioselective dihydroxylation and epoxidation of styrene derivatives was obtained by using $\mathrm{Ru}$ or Os complexes linked with bovine serum albumin (BSA, Leurs et al., 2018, Table 1.3, Figure 1C). Also, by coordination of the monocavitin, based on an $\mathrm{Fe}_{4}(\mathrm{Zn}-\mathrm{L})_{6}$ cage to rhodium, efficient hydroformylation catalysts $\mathrm{Rh}_{\mathrm{F}} \mathrm{Fe}_{4}(\mathrm{Zn}-\mathrm{L})_{6}$, that shows excellent product selectivity, has been obtained (Nurttila et al, 2019; Table 1.4, Figure 1D). For the case of N-heterocyclic carbene-capped $\mathrm{CD}$ gold complexes (Figure 1E). (ICD) $\mathrm{Au} \mathrm{Cl}$ stereoselectivity in enyne-cycloisomerization depends on the nature of the cyclodextrin: $\alpha-\mathrm{ICD}$ and $\beta$ - ICD give the enantiomer for which the approach is the easiest according to their helical shape, and $\gamma$ - ICD does not afford enantioselectivity because of its symmetrical shape (Roland et al., 2018; Table 1.5, Figure 1E). The incorporation of iron porphyrin and L- or D-histidines endows chiral COF nanozymes with high activity and selectivity in the peroxidase oxidation of dopa enantiomers (Figure 1F). This artificial peroxidase possesses 21.7 times higher activity than natural HRP (Zhou et al., 2020). "Substrate selectivity is more difficult to rationalize for small molecules, such as $\mathrm{H}_{2}, \mathrm{O}_{2}$, $\mathrm{CO}_{2}$, and $\mathrm{CH}_{4}$, which possess too narrow a range of physical characteristics to allow either precise positioning or discrimination between reactants. Nevertheless, metalloenzymes have evolved to metabolize these small-molecule substrates with high selectivity and efficiency due to small-molecule tunnels and gate-effects. It delivers the right substrate to the right location at the right time, for example, for selective oxidation of the strongest aliphatic hydrocarbon bond in methane" (Banerjee and Lipscomb, 2021). "Also for the small molecule discussed here, the spatial and temporal control of delivery of protons and electrons to the active site is crucial to maintain product selectivity in these transformations" (Amanullah et al., 2021). The activation of small molecules, such as $\mathrm{CO}_{2}, \mathrm{~N}_{2}, \mathrm{O}_{2}$, and $\mathrm{CH}_{4}$, has always been a dream in chemistry. The modern challenges of climate change, energy deficit, and quality of the fossil resources used make the transformation of these small molecules more important than ever before. M-cavitins demonstrate high activities for energetically challenging reactions with participation of small gas molecules and high selectivity to valuable products. This explains the great interest in these processes and rapid development of advanced catalysts for the activation of small molecules, such as $\mathrm{H}_{2} \mathrm{O}, \mathrm{CO}_{2}$ and $\mathrm{CH}_{4}$, in recent years.

\section{$\mathrm{H}_{2} \mathrm{O}$ AND ARTIFICIAL PHOTOSYNTHESIS}

Water in combination with sunlight can serve as a source of cheap and clean energy, provided that artificial photosynthesis is mastered. The challenges of the incumbent energy crisis and environmental problems can be solved via photochemical, 
A

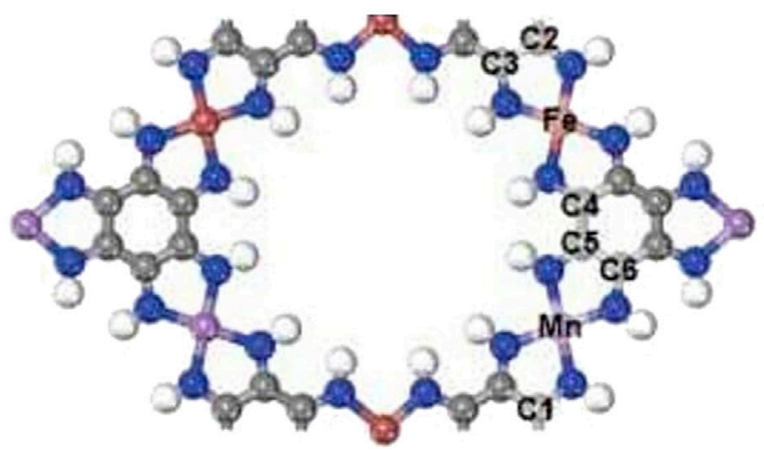

C

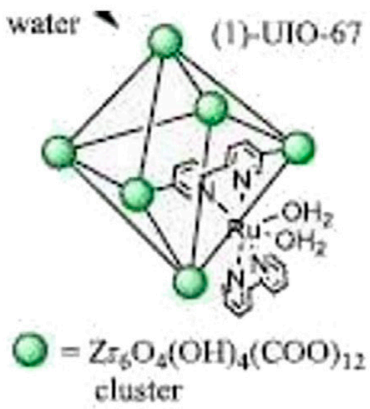

F

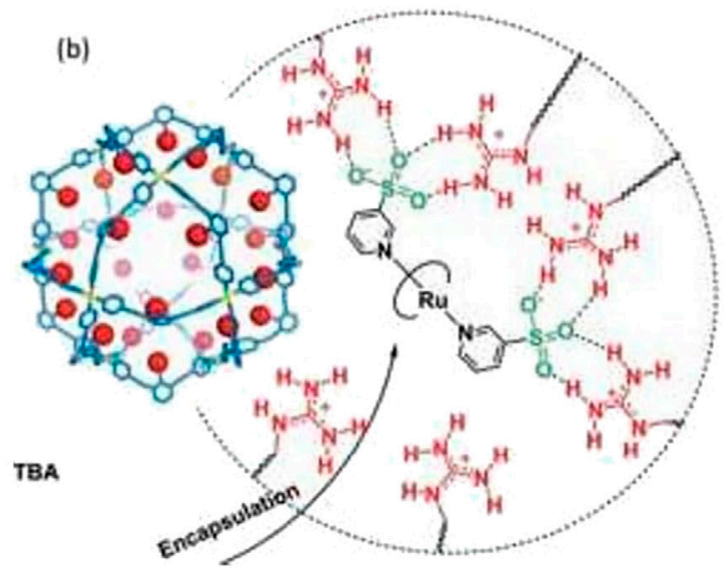

B

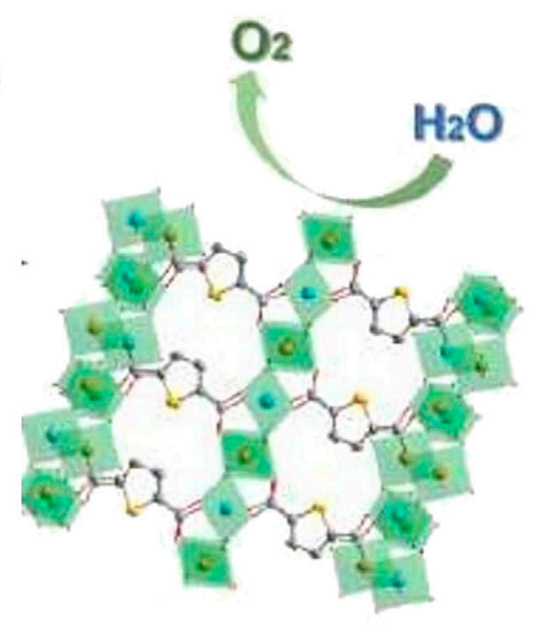

E

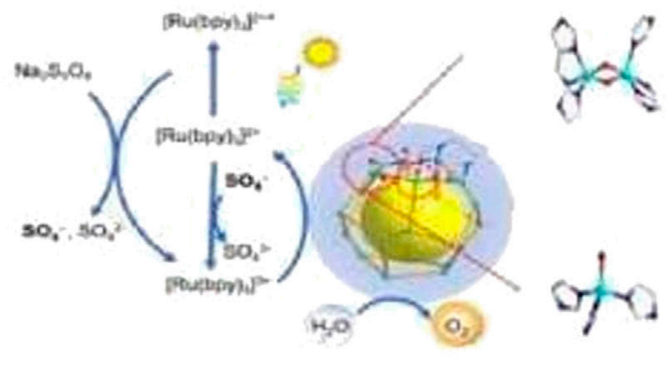

G

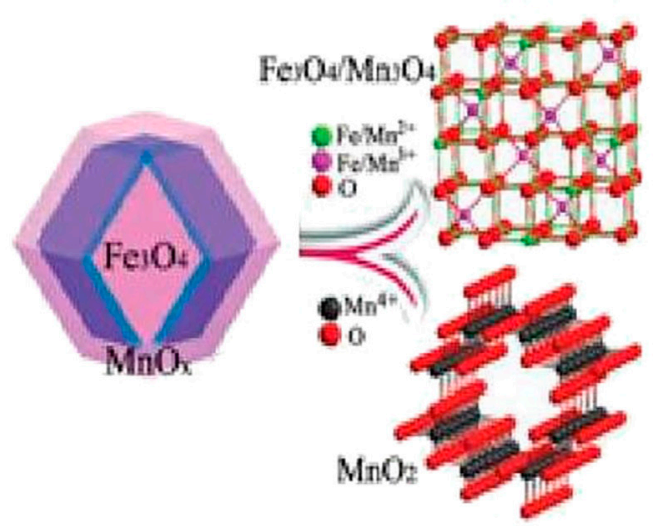

FIGURE 2 | MC for WS and O reduction. (A) Mn/Fe-hexaiminobenzene MOF for electrocatalytic oxygen reduction reaction and OER (Shinde et al, 2019). (B) Fe-Ni MOF electrocatalyst for water oxidation (Wang K. et al, 2021). (C) Active water oxidation catalyst cis-[Ru(bpy) $\left(5,5^{\prime} \text { dcbpy) }\left(\mathrm{H}_{2} \mathrm{O}\right)_{2}\right]^{2+}(1)$ incorporated into UIO-67 MOF (Ezhov et al, 2020) (D) Cu-core of the bioinspired catalyst for water oxidation (Chen Z. -Y. et al, 2021). (E) Co-based MOC for photo-driven water oxidation (Chen Q. F. et al. 2021). (F) Preorganization of the ruthenium catalyst in self-assembled nanospheres for electrochemical water oxidation (Yu et al, 2018). (G) Hierarchical Fe-Mn binary metal oxide core-shell nano-polyhedron for electrochemical WS (Li et al, 2021).

electrochemical, and photoelectrochemical water splitting (WS) to produce oxygen and hydrogen green fuels. For the realization of artificial photosynthesis, it is "necessary to develop the design of WS catalysts that can be incorporated into future sunlight-tochemical fuel assemblies" (Ezhov et al., 2020). WS involves two reactions: oxygen evolution reaction (OER) and hydrogen evolution reaction (HER). Photoinduced WS into oxygen and hydrogen is one of the most interesting pathways for solving the incumbent society problems. A porphyrinic zirconium MOF nanotube HNTM-Ir/Pt possessed a high photocatalytic HER 
rate of $201.9 \mathrm{mmol} \mathrm{g}^{-1} \mathrm{~h}^{-1}$ and better recycling stability under visible light irradiation in WS than earlier HNTM-Pt or HNTMIr (He et al., 2018). The double-shelled $\mathrm{TiO}_{2} @ Z I F-8$ hollow spheres used for HER under illumination show an efficient charge separation by electron injection from ZIF-8 to $\mathrm{TiO}_{2}$, high photocatalytic quantum efficiencies of $50.89 \%$ at $380 \mathrm{~nm}$, and high HER rate up to $261.7 \mathrm{mmol} \mathrm{g}^{-1} \mathrm{~h}^{-1}$, which is 3.5 times higher than that of bare $\mathrm{TiO}_{2}$ (Qiu et al., 2021). Donor-acceptor imine-linked COFs produce hydrogen with a rate $20.7 \mathrm{mmol} \mathrm{g}^{-1} \mathrm{~h}^{-1}$ under visible light irradiation due to protonation of their imine linkages and improved charge separation efficiency (Yang et al., 2021b). Electrocatalytic WS has been regarded as another promising approach for producing hydrogen and oxygen under mild conditions. An Fe-Cu layered double hydroxide integrated with a Co MOF ZIF-12 to form LDH-ZIF-12 composite shows enhanced OER performance as compared to individual components, that is, $\mathrm{Fe}-\mathrm{Cu}-\mathrm{LDH}$ and ZIF-12. Chronoamperometric studies show that this composite leads to a higher current density and low overpotential, and is an efficient and stable electrocatalyst for commercial use (Hameed et al., 2021). The multi-shelled hollow $\mathrm{Mn} / \mathrm{Fe}$-hexaiminobenzene MOF (Mn/Fe-HIB-MOF) (Figure 2A) is an excellent bifunctional electrocatalyst for dioxygen reduction reaction and OER. It has better performance than commercial $\mathrm{RuO}_{2}$, Mn-HIB-MOF, and Fe-HIB-MOF catalysts (Shinde et al., 2019)]. The Fe-Ni-MOF show remarkable electrocatalytic performance with a low overpotential of $266 \mathrm{mV}$ at $100 \mathrm{~mA} \mathrm{~cm}^{-2}$ and a high TOF value of $0.261 \mathrm{~s}^{-1}$ for water oxidation (Figure 2B, Wang C.P. et al, 2021). The iridacycle-decorated COF shows 10-fold efficiency enhancement in photocatalytic hydrogen evolution from aqueous formate solution in comparison with its molecular counterpart under mild conditions (Hu et al., 2021). Photoinduced water oxidation by MOFs has been widely studied in the past few years. The active water oxidation catalyst cis[Ru(bpy) (5,5'-dcbpy) $\left.\left(\mathrm{H}_{2} \mathrm{O}\right)_{2}\right]^{2+}$ was incorporated into UIO-67 MOFs using postsynthetic modification of the framework (Figure 2C). XAS, EPR, and Raman spectroscopy confirmed the formation of $\mathrm{M}$-cavitin and the highly active $\mathrm{Ru}^{\mathrm{V}}=\mathrm{O}$ key intermediate (Ezhov et al., 2020). A bioinspired trinuclear copper catalyst developed recently for water oxidation displays a TOF value of $20000 \mathrm{~s}^{-1}$, which is 150 times and 15 times higher than that of the mono- and the bis- $\mathrm{Cu}$ complexes, respectively (Figure 2D; Chen Q.-F. et al, 2021). Also, four MOCs based on cobalt ions and imidazolate ligands were studied recently on photo-driven water oxidation for the first time (Chen Z.-Y. et al, 2021). These studies revealed that photoinduced water oxidation starts via $\mathrm{e}^{-}$transfer from the excited $\left[\mathrm{Ru}(\mathrm{bpy})_{3}\right]^{2+\star}$ to $\mathrm{Na}_{2} \mathrm{~S}_{2} \mathrm{O}_{8}$ and then to the bis ( $\mu$-oxo) dicobalt active sites which further donate electrons to the oxidized $\left[\mathrm{Ru}(\mathrm{bpy})_{3}\right]^{3+}$ to drive water oxidation (Figure 2E). Self-assembled nanospheres with guanidinium binding sites form sulfonate-functionalized preorganized ruthenium catalysts for electrochemical water oxidation, which leads to an increase in the reaction rate by almost 100 times compared to a homogenous system (Figure 2F) (Yu et al., 2018). Hierarchical bifunctional catalysts for WS are undoubtedly the most promising catalysts of the low-carbon energy future. Such a $\mathrm{Fe}_{3} \mathrm{O}_{4} @ \mathrm{MnO}_{\mathrm{x}}$ binary metal oxide core-shell nano-polyhedron fabricated recently (Figure 2F, Li et al., 2021) involves cathodic $2 \mathrm{e}^{-}$HER and anodic $4 \mathrm{e}^{-}$OER and has a low HER/OER overpotential of 242/188 $\mathrm{mV}\left(10 \mathrm{~mA} \mathrm{~cm}^{-2}\right)$,

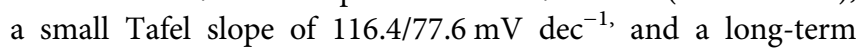
cyclability of $5 \mathrm{~h}$. By applying this catalyst as an independent cathode and anode, the overall WS cell supplies a competitive voltage of $1.64 \mathrm{~V}$ to achieve $10 \mathrm{~mA} \mathrm{~cm}^{-2}$ and good work stability of $80 \mathrm{~h}$. Another example is $\mathrm{Fe}$-doped $\mathrm{NiCo}_{2} \mathrm{O}_{4} / \mathrm{Ni}_{3} \mathrm{~S}_{4}$ hollow heterostructure nanotubes which implement highly efficient electrocatalytic overall WS with low overpotential of $29.1 \mathrm{mV}$ $\left(10 \mathrm{~mA} \mathrm{~cm}^{-2}\right)$, a relatively small Tafel slope of $53.3 \mathrm{mV} \mathrm{dec}^{-1}$ for the HER, and $259 \mathrm{mV}$ at a current density of $100 \mathrm{~mA} \mathrm{~cm}^{-2}$ (33.1 $\mathrm{mV} \mathrm{dec}^{-1}$ ) for the OER (Liu et al., 2021).

\section{$\mathrm{CO}_{2}$ AND METHANE}

Mastering artificial photosynthesis includes along with photolytic WS also solar light harvesting and photochemical reduction of carbon dioxide $\left(\mathrm{CO}_{2} \mathrm{R}\right)$. The light harvesting systems based on supramolecular assembly in aqueous media contain lightabsorbing chromophores which gather and convert the excitation energy to chemical energy via energy transfers from donors to acceptors. Some cavitins, for example, hydrophobic macrocycles, such as $\mathrm{CD}$ and calixarenes, play a prominent role in forming these supramolecular systems (Wang $\mathrm{H}$ et al., 2021). The photochemical $\mathrm{CO}_{2} \mathrm{R}$ was studied for a number of MCs. In cavitins, the transition state of the target reaction can be stabilized more efficiently in comparison with bulk solution. Thus, Ir complex incorporated into $\mathrm{Zr}-\mathrm{MOC}-\mathrm{NH}_{2}$ was used for $\mathrm{CO}_{2}$ photoreduction. DFT calculations and in situ IR show that the $\mathrm{Ir}$ (III) complex is the catalytic center and $-\mathrm{NH}_{2}$ in the cavity plays a synergetic role in the stabilization of the transition state and $\mathrm{Ir} \cdot \mathrm{CO}_{2}$ intermediate (Qi et al., 2021). Under irradiation by visible light, the single Ir ${ }^{\mathrm{III}}-\mathrm{MOC}-\mathrm{NH}_{2}$ cage can convert $\mathrm{CO}_{2}$ into CO with a selectivity of $99.5 \%$ and a TOF of $120 \mathrm{~h}^{-1}$, which is 3.4 times higher that of bulk $\mathrm{Ir}$ (III) complex and 100 times higher than that of the classical MOF counterpart, Ir ${ }^{\mathrm{II}}$-Uio-67- $\mathrm{NH}_{2}$ (Figure 3A, Qi et al., 2021). Photocatalytic $\mathrm{CO}_{2} \mathrm{R}$ with the MIL$100(\mathrm{Fe})-\mathrm{CsPbBr} \mathrm{P}_{3}$ composite having a high specific surface area, an enhanced solar light response, and an improved charge carrier separation resulted in an excellent photocatalytic performance with $20.4 \mu \mathrm{mol} \mathrm{CO}$ produced per gram of the photocatalyst during 1 hour under visible light irradiation (Cheng et al., 2020). Anionic MOFs as a host and a cationic photosensitizer as a guest were self-assembled into a photocatalytic system, Ru@ $\mathrm{Cu}$-HHTP, which showed high activity for photocatalytic $\mathrm{CO}_{2} \mathrm{R}$ under sunlight with $\mathrm{CO}$ selectivity of $91.3 \%$ (Figure 3B, Huang et al., 2021). An Ni-MOF-derived catalyst for the light-driven methanation of $\mathrm{CO}_{2}$ produces methane with a rate of $488 \mathrm{mmol} \mathrm{g}^{-1} \mathrm{~h}^{-1}$ under UV-visible-IR irradiation and displayed excellent recyclability without loss of catalytic activity (Khan et al., 2021). Because of the highly stacked layers, some COFs have semiconductive properties and exhibit good catalytic performance in photo- $\mathrm{CO}_{2} \mathrm{R}$ (Nguyen and Alzamly, 2021). The d-UiO-66/MoS ${ }_{2}$ composite implements the photocatalytic conversion of $\mathrm{CO}_{2}$ and $\mathrm{H}_{2} \mathrm{O}$ to $\mathrm{CH}_{3} \mathrm{COOH}$ 
A

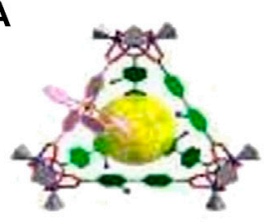

C

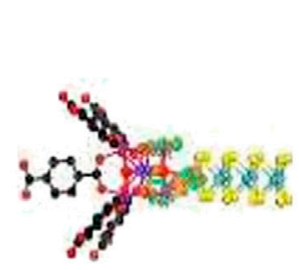

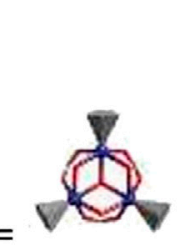

D
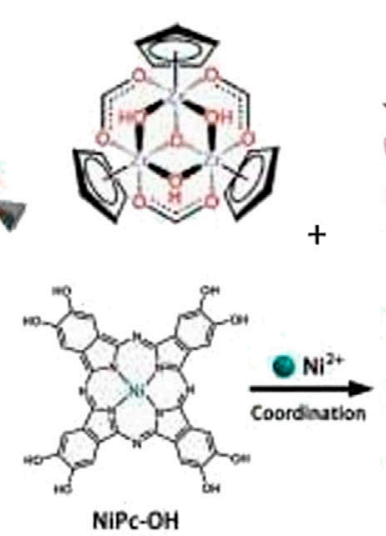
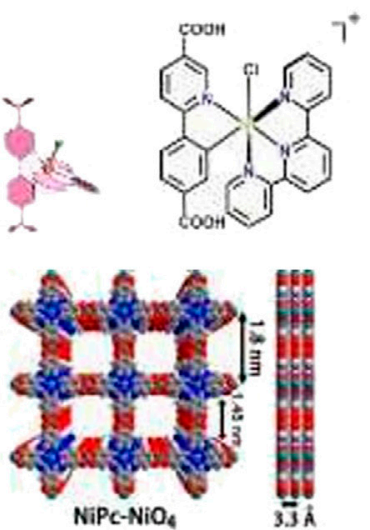

B

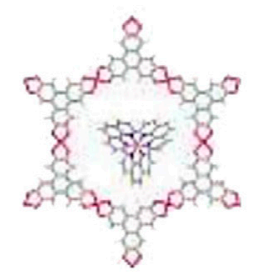

E

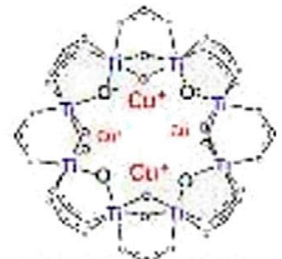

MIL-125-N $\mathrm{NH}_{2}-\mathrm{CU}^{\prime}-4$
F

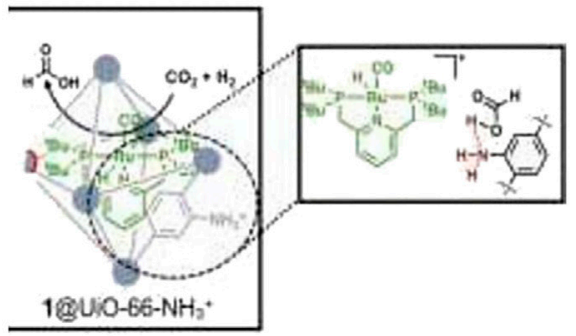

G
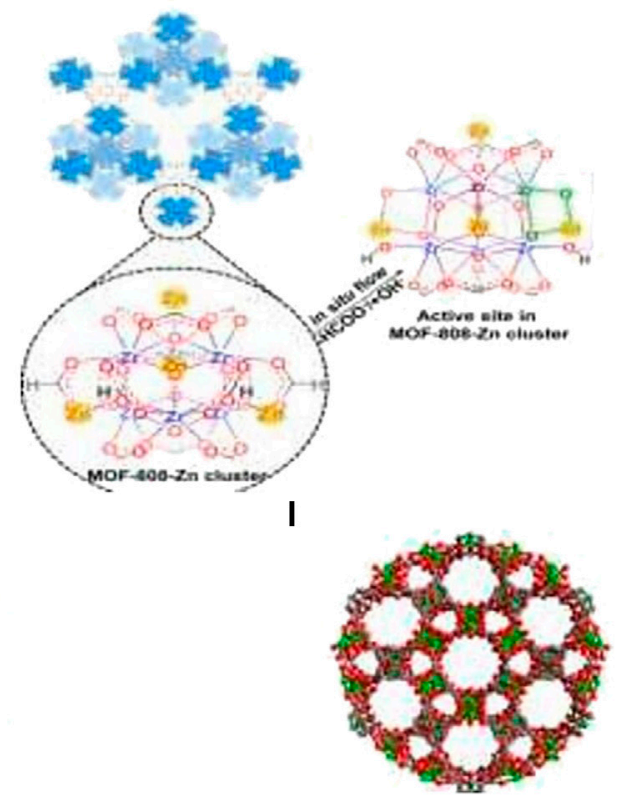

FIGURE 3 | MC for $\mathrm{CO}_{2}$ transformations: (A) MOC decorated with an Ir(III) complex for $\mathrm{CO}_{2}$ photoreduction. (B) Electrostatic attraction-driven assembly of MOF with a photosensitizer for photocatalytic $\mathrm{CO}_{2}$ reduction to $\mathrm{CO}$ (Huang et al, 2021). (C) Hierarchically porous d-UiO-66/MoS ${ }_{2}$ for selective conversion of $\mathrm{CO}_{2}$ with $1-120$ into $\mathrm{CH}_{3} \mathrm{COOH}$ (YU T. et al, 2021). (D) Conductive two-dimensional phthalocyanine-based MOF nanosheets linked by nickel-catecholate for $\mathrm{CO}_{2}$ electroreduction. (E) Multiple cuprous centers supported on Ti-MOF for $\mathrm{CO}_{2}$ hydrogenation to ethylene (Zeng et al, 2021). (F) Multicomponent catalyst system based on MOF UiO-66 for the hydrogenation of carbon dioxide to methanol (Rayder et al, 2021). (G) MOF-808-Zn catalyst for $\mathrm{CO}_{2}$ hydrogenation (Zhang H. et al, 2021). (H) Bifunctional MetalOrganic Layers for tandem catalytic transformations using molecular oxygen and carbon dioxide (Shi et al, 2021). (I) COF assembled from 12-nuclear [Cu ${ }^{12}$ ] nanocages with two types nanotubular channels for a catalysis the cycloaddition of $\mathrm{CO}_{2}$ to various epoxides (Wang K. et al, 2021).

under visible light. The evolution rate and selectivity of $\mathrm{CH}_{3} \mathrm{COOH}$ reached $39.0 \mathrm{mmol} \mathrm{g}^{-1} \mathrm{~h}^{-1}$ and $94 \%$, respectively, without any $\mathrm{C} 1$ products (Figure 3C, Yu F. et al, 2021). Electrochemical $\mathrm{CO}_{2} \mathrm{R}$ has also been proven to be a promising strategy among various types of energy conversion. A desired electrocatalyst should have a high TON, a high TOF, and low overpotential (Zhang H. et al, 2021). The Zn-based MOF CALF20 demonstrates the highest CO Faradaic efficiency of $94.5 \%$ at $-0.97 \mathrm{~V}$ vs. RHE with a TOF of $1360.8 \mathrm{~h}^{-1}$ and a partial current density of $-32.8 \mathrm{~mA} / \mathrm{cm}^{2}$ for electrochemical $\mathrm{CO}_{2} \mathrm{R}$ to $\mathrm{CO}$ (Al-Attas et al., 2021). The redox-active In-MOF shows the first example of an Ni-based MOF catalyst in electrocatalytic $\mathrm{CO}_{2} \mathrm{R}$, which suggests new prospects for designing novel and efficient non-noble, metal-based, redox-active, biomimetic MOFs (Zhou et al., 2021). Conductive phthalocyanine-based MOF $\left(\mathrm{NiPc}-\mathrm{NiO}_{4}\right)$ nanosheets linked by nickel-catecholate are highly efficient electrocatalysts for the $\mathrm{CO}_{2} \mathrm{R}$ to $\mathrm{CO}$


good conductivity and exhibited a selectivity of $98.4 \%$ toward $\mathrm{CO}$ production and a large $\mathrm{CO}$ partial current density of $34.5 \mathrm{~mA} \mathrm{~cm}^{-2}$, outperforming the reported MOF catalysts (Yi et al., 2021). Hydrogenation of $\mathrm{CO}_{2}$ to valuable chemicals may also be of great interest for the implementation of a sustainable carbon cycle. Multiple $\mathrm{Cu}$ centers supported on Ti-MOF (Figure 3E) catalyze $\mathrm{CO}_{2}$ hydrogenation to ethylene. Zeng et al., (2021) present a new tandem route for $\mathrm{CO}_{2}$-to- $\mathrm{C}_{2} \mathrm{H}_{4}$ 
conversion via $\mathrm{CO}_{2}$ hydrogenation to ethanol followed by its dehydration. The catalyst exhibits high ethylene selectivity, that is, $>90 \%$. The MOF UiO-66 was used in tandem with its zirconium oxide nodes and an incorporated ruthenium PNP pincer complex to hydrogenate $\mathrm{CO}_{2}$ to $\mathrm{HCOOH}$, then to $\mathrm{CH}_{3} \mathrm{OH}$, giving the highest reported TON 19000 and TOF $9100 \mathrm{~h}^{-1}$. Moreover, the reaction was readily recyclable, leading to a cumulative TON of 100,000 after 10 reaction cycles (Figure 3F, Rayder et al., 2021). The neighboring $\mathrm{Zn}^{2+}$ $\mathrm{O}-\mathrm{Zr}^{4+}$ sites obtained by postsynthetic treatment of $\mathrm{Zr}_{6}\left(\mu_{3}-\right.$ O) ${ }_{4}\left(\mu_{3}-\mathrm{OH}\right)_{4}$ nodes of MOF-808 by $\mathrm{ZnEt}_{2}$ gave the MOF$808-\mathrm{Zn}$ catalyst, which exhibits $>99 \% \mathrm{MeOH}$ selectivity in $\mathrm{CO}_{2}$ hydrogenation at $250^{\circ} \mathrm{C}$ and a high space-time yield of up to $190.7 \mathrm{mg} \mathrm{MeOH} \mathrm{g}_{\mathrm{Zn}}{ }^{-1} \mathrm{~h}^{-1}$ and exhibited excellent stability for at least $100 \mathrm{~h}$ (Figure 3G, Zhang Y. et al, 2021). Bifunctional MOF containing tripyridyl complexes of $\mathrm{Fe}$ and $\mathrm{Mn}$ converts styrenes into styrene carbonates via tandem epoxydation using $\mathrm{O}_{2}$ and then $\mathrm{CO}_{2}$ insertion and also effectively transforms alkylaromatic hydrocarbons into cyanohydrins via involvement of a high-spin $\mathrm{Fe}^{\mathrm{IV}}(\mathrm{S}=2)$ center in the challenging oxidation of the sp3 $\mathrm{C}-\mathrm{H}$ bond. (Figure 3H, Shi et al., 2021). A new porous COF assembled from 12-nuclear $\left[\mathrm{Cu}_{12}\right]$ nanocages $\left\{\left[\mathrm{Cu}_{2}\left(\mathrm{~L}^{4-}\right)\left(\mathrm{H}_{2} \mathrm{O}\right)_{2}\right]\right.$. $\left.4 \mathrm{DMA} \cdot 2 \mathrm{H}_{2} \mathrm{O}\right\}_{\mathrm{n}}$ with two types of nanotubular channels and a large specific surface area effectively catalyzes the cycloaddition of $\mathrm{CO}_{2}$ to various epoxides under mild conditions (Figure 3I, Wang W.-M. et al, 2021). Carbonylation reactions are of particular importance for organic synthesis. The use of $\mathrm{CO}_{2}$ in the carbonylation reaction catalyzed by composite $\left(\mathrm{Cu}_{1} \mathrm{Pd}_{2}\right)_{\mathrm{z}} @ \mathrm{PCN}-222(\mathrm{Co})$ allows the photosynthesis of benzophenone with $90 \%$ yield and $97 \%$ selectivity under mild conditions (Fu et al., 2021). Cavitins are of interest in the development of tandem methylation reactions utilizing $\mathrm{CO}_{2}$ as a one-carbon building block that would enable a more sustainable chemical industry (Rooney et al., 2021). The development of the direct low-temperature selective oxidation of methane to methanol has remained an active area of research over the last 50 years (Shteinman, 2020). Compared to WS and $\mathrm{CO}_{2}$ conversion, the effective and selective chemical routes to valorize methane with participation of cavitins are relatively less elaborated. Direct methane conversion has been carried out in the gas phase over $\mathrm{Cu}$ - and $\mathrm{Fe}$ containing zeolites in the stepwise cyclic process that involves activating the transition metal with $\mathrm{O}_{2}$ or $\mathrm{N}_{2} \mathrm{O}$ at $400-500^{\circ} \mathrm{C}$, then methane reaction with active intermediates at $200^{\circ} \mathrm{C}$, and finally product extraction with water steam. However, the rate and productivity of these processes are still very low (Shteinman, 2020). Catalytic processes for the hydroxylation of methane on zeolite $\mathrm{Fe}-\mathrm{Cu}-\mathrm{ZSM}-5$ with a selectivity of $20-80 \%$ under aqueous conditions at $50^{\circ} \mathrm{C}$ using $\mathrm{H}_{2} \mathrm{O}_{2}$ were proposed (Hammond et al., 2012; Yu T. et al, 2021). The $\mathrm{Cu}-\mathrm{Fe}(2 / 0.1) / Z S M-5$ catalyst is an efficient catalyst for the direct conversion of methane into methanol in the liquid phase using $\mathrm{H}_{2} \mathrm{O}_{2}$, which exhibits an excellent methanol productivity of $431 \mathrm{~mol}_{\mathrm{MeOH}} \cdot \mathrm{mol}_{\mathrm{Fe}}^{-1} \cdot \mathrm{h}^{-1}$ and methanol selectivity of $80 \%$.
The mechanism based on catalytic, spectroscopic, and theoretical results was suggested (Yu T. et al, 2021): the acid sites adjacent to iron Bronsted contribute to the formation of an active $\mathrm{Fe}(\mathrm{V})=\mathrm{O}$ intermediate via the dehydration of formed $\mathrm{Fe}-\mathrm{OOH}$ in the aqueous $\mathrm{H}_{2} \mathrm{O}_{2}$ solution, enabling the homolytic cleavage of the primary $\mathrm{C}-\mathrm{H}$ by radical-rebound mechanism to generate $\bullet \mathrm{CH}_{3}$ radicals that are quickly captured by $\bullet \mathrm{OH}$ radicals to form $\mathrm{CH}_{3} \mathrm{OH}$. Contrary to $\mathrm{Cu}-$ and Fe-containing zeolites, the study of MOF-based MMO mimics is still at the early stage and suffers from the same problems which are low productivity and rate and low methanol selectivity due to overoxidation (Shteinman, 2020).

\section{SUMMARY, DISCUSSION, AND PERSPECTIVE}

Cavities and other holes are ubiquitous in the material world. Enzymes are inherently natural cavitins. Chemical cavitins have emerged due to efforts of synthetic and supramolecular chemists. M-cavitins demonstrate high activities for energetically challenging reactions. Much information has already been accumulated on the photocatalytic and electrochemical conversion of energy for the ecological production of fuels, materials, and chemicals. Still, looking ahead, innovative solutions are still needed to overcome the global energy crisis and improve the environment. The solution of these problems is primarily connected with the development of fundamental scientific research of bioinspired catalysts. These studies will require completely new solutions for the design and synthesis of a more diverse library of $\mathrm{M}$-cavitins with innovative structures, metal ion composition, and functionality. Despite many achievements of electrocatalytic WS, highly active and durable catalysts have to be developed to overcome the kinetic barriers in this process, especially for the OER (Zhang H. et al, 2021). Electrocatalysis of other abundant resources, such as methane, is now increasingly coming into focus. In this area much research remains to be carried out. In particular, efforts to delineate reaction mechanisms and extract the fundamental insights are necessary to develop economically competitive electrosynthetic routes using methane. Though there still remains a considerable gap between academic research and industrial applicability, the fundamental research covered here with atomically precise catalytic systems serves as a promising foundation for the future (Zhang $\mathrm{H}$ et al., 2021). Using visible light irradiation to reduce $\mathrm{CO}_{2}$ to $\mathrm{C}$-based products is an environmental and economic method which transforms solar energy in the form of chemical bonds. COF chemistry has been exponentially explored during the last several years, and the photocatalytic $\mathrm{CO}_{2} \mathrm{R}$ processes catalyzed by COF materials are in their early stage (Nguyen and Alzamly, 2021). The direct oxidation of methane in a laboratory setup with participation of $\mathrm{M}$-cavitins using mild conditions is still a challenging problem. There is still a huge gap between MMO enzymes and chemical catalysts based on M-cavitins both in activity and selectivity and also, importantly, in the mechanism of direct oxidation of methane to methanol. 


\section{AUTHOR CONTRIBUTIONS}

The author confirms being the sole contributor of this study and has approved it for publication.

\section{REFERENCES}

Al-Attas, T. A., Marei, N. N., Yong, X., Yasri, N. G., Thangadurai, V., Shimizu, G., et al. (2021). Ligand-Engineered Metal-Organic Frameworks for Electrochemical Reduction of Carbon Dioxide to Carbon Monoxide. ACS Catal. 11, 7350-7357. doi:10.1021/acscatal.1c01506

Amanullah, S., Saha, P., Nayek, A., Ahmed, M. E., and Dey, A. (2021). Biochemical and Artificial Pathways for the Reduction of Carbon Dioxide, Nitrite and the Competing Proton Reduction: Effect of 2nd Sphere Interactions in Catalysis. Chem. Soc. Rev. 50, 3755-3823. doi:10.1039/d0cs01405b

Banerjee, R., and Lipscomb, J. D. (2021). Small-Molecule Tunnels in Metalloenzymes Viewed as Extensions of the Active Site. Acc. Chem. Res. 54, 2185-2195. doi:10.1021/acs.accounts.1c00058

Bavykina, A., Kolobov, N., Khan, I. S., Bau, J. A., Ramirez, A., and Gascon, J. (2020). Metal-Organic Frameworks in Heterogeneous Catalysis: Recent Progress, New Trends, and Future Perspectives. Chem. Rev. 120 (16), 8468-8535. doi:10.1021/ acs.chemrev.9b00685

Chen, Q.-F., Cheng, Z.-Y., Liao, R.-Z., and Zhang, M.-T. (2021). Bioinspired Trinuclear Copper Catalyst for Water Oxidation with a Turnover Frequency up to 20000 S-1. J. Am. Chem. Soc. 143, 19761-19768. doi:10.1021/jacs.1c08078

Chen, Z.-Y., Long, Z.-H., Wang, X.-Z., Zhou, J.-Y., Wang, X.-S., Zhou, X.-P., et al. (2021). Cobalt-Based Metal-Organic Cages for Visible-Light-Driven Water Oxidation. Inorg. Chem. 60, 10380-10386. doi:10.1021/acs.inorgchem.1c00907

Cheng, R., Debroye, E., Hofkens, J., and Roeffaers, M. B. J. (2020). Efficient Photocatalytic $\mathrm{CO}_{2}$ Reduction with MIL-100(Fe)-CsPbBr 3 Composites. Catalysts 10, 1352. doi:10.3390/catal10111352

Ezhov, R., Karbakhsh Ravari, A., Page, A., and Pushkar, Y. (2020). Water Oxidation Catalyst Cis-[Ru(bpy) $\left(5,5^{\prime}\right.$-dcbpy $\left.)\left(\mathrm{H}_{2} \mathrm{O}\right) 2\right]^{2+}$ and Its Stabilization in MetalOrganic Framework. ACS Catal. 10, 5299-5308. doi:10.1021/acscatal.0c00488

Feng, X., Song, Y., Chen, J. S., Xu, Z., Dunn, S. J., and Lin, W. (2021). Rational Construction of an Artificial Binuclear Copper Monooxygenase in a MetalOrganic Framework. J. Am. Chem. Soc. 143, 1107-1118. doi:10.1021/ jacs.0c11920

Fu, S., Yao, S., Guo, S., Guo, G.-C., Yuan, W., Lu, T.-B., et al. (2021). Feeding Carbonylation with $\mathrm{CO}_{2}$ via the Synergy of Single-Site/Nanocluster Catalysts in a Photosensitizing MOF. J. Am. Chem. Soc. 143, 20792-20801. doi:10.1021/ jacs.1c08908

Hameed, A., Batool, M., Iqbal, W., Abbas, S., Imran, M., Khan, I. A., et al. (2021). ZIF-12/Fe-Cu LDH Composite as a High Performance Electrocatalyst for Water Oxidation. Front. Chem. 9, 686968. doi:10.3389/fchem.2021.686968

Hammond, C., Forde, M. M., Ab Rahim, M. H., Thetford, A., He, Q., Jenkins, R. L., et al. (2012). Direct Catalytic Conversion of Methane to Methanol in an Aqueous Medium by Using Copper-Promoted Fe-ZSM-5. Angew. Chem. Int. Ed. 51, 5129-5133. doi:10.1002/anie.201108706

He, T., Chen, S., Ni, B., Gong, Y., Wu, Z., Song, L., et al. (2018). ZirconiumPorphyrin-Based Metal-Organic Framework Hollow Nanotubes for Immobilization of Noble-Metal Single Atoms. Angew. Chem. Int. Ed. 57, 3493-3498. doi:10.1002/anie.201800817

Heerden, D. P., Smith, V. J., Aggarwal, H., and Barbour, L. J. (2021). High Pressure In Situ Single-Crystal X-Ray Diffraction Reveals Turnstile Linker Rotation Upon Room-Temperature Stepped Uptake of Alkanes. Angew. Chem. Int. Ed. 60, 13430-13435. doi:10.1002/anie.202102327

Holsten, M., Feierabend, S., Elbert, S. M., Rominger, F., Oeser, T., and Mastalerz, M. (2021). Soluble Congeners of Prior Insoluble Shape Persistent Imine Cages. Chem. Eur. J. 27, 9383-9390. doi:10.1002/chem.202100666

Hou, B., Yang, S., Yang, K., Han, X., Tang, X., Liu, Y., et al. (2021). ConfinementDriven Enantioselectivity in 3D Porous Chiral Covalent Organic Frameworks. Angew. Chem. Int. Ed. 60, 6086-6093. doi:10.1002/anie.202013926

Hu, J., Mehrabi, H., Meng, Y.-S., Taylor, M., Zhan, J.-H., Yan, Q., et al. (2021). Probe Metal Binding Mode of Imine Covalent Organic Frameworks:

\section{FUNDING}

This study was supported by the Russian Ministry of Science and Education (Project No. AAAA-A19-119071190045-0).

Cycloiridation for (Photo)catalytic Hydrogen Evolution from Formate. Chem. Sci. 12, 7930-7936. doi:10.1039/d1sc01692j

Huang, N.-Y., He, H., Liu, S., Zhu, H.-L., Li, Y.-J., Xu, J., et al. (2021). Electrostatic Attraction-Driven Assembly of a Metal-Organic Framework with a Photosensitizer Boosts Photocatalytic $\mathrm{CO}_{2}$ Reduction to CO. J. Am. Chem. Soc. 143, 17424-17430. doi:10.1021/jacs.1c05839

Khan, I. S., Mateo, D., Shterk, G., Shoinkhorova, T., Poloneeva, D., Garzón Tovar, L., et al. (2021). An Efficient Metal-Organic Framework Derived Nickel Catalyst for the Light Driven Methanation of $\mathrm{CO}_{2}$. Angew. Chem. Int. Ed. 60, 26476-26482. doi:10.1002/anie.202111854

Leenders, S. H. A. M., Gramage-Doria, R., de Bruin, B., and Reek, J. N. H. (2015). Transition Metal Catalysis in Confined Spaces. Chem. Soc. Rev. 44, 433-448. doi: $10.1039 / \mathrm{c} 4 \mathrm{cs} 00192 \mathrm{c}$

Leurs, M., Dorn, B., Wilhelm, S., Manisegaran, M., and Tiller, J. C. (2018). Multicore Artificial Metalloenzymes Derived from Acylated Proteins as Catalysts for the Enantioselective Dihydroxylation and Epoxidation of Styrene Derivatives. Chem. Eur. J. 24, 10859-10867. doi:10.1002/ chem.201802185

Li, M., Chen, J., Wu, W., Fang, Y., and Dong, S. (2020). Oxidase-like MOF-818 Nanozyme with High Specificity for Catalysis of Catechol Oxidation. J. Am. Chem. Soc. 142, 15569-15574. doi:10.1021/jacs.0c07273

Li, Y.-W., Su, S.-K., Yue, C.-Z., Shu, J., Zhang, P.-F., Du, F.-H., et al. (2021). Hierarchical Fe-Mn Binary Metal Oxide Core-Shell Nano-Polyhedron as a Bifunctional Electrocatalyst for Efficient Water Splitting. Dalton Trans. 50, 17265-17274. doi:10.1039/d1dt03048e

Liu, Z., Zhao, B., Pan, C., and Zhao, H. (2021). Binder-free Fe-Doped NiCo2O4/ Ni3S4 Hollow Heterostructure Nanotubes for Highly Efficient Overall Water Splitting. Dalton Trans. 50, 18155-18163. doi:10.1039/d1dt02904e

Nguyen, H. L., and Alzamly, A. (2021). Covalent Organic Frameworks as Emerging Platforms for $\mathrm{CO}_{2}$ Photoreduction. ACS Catal. 11, 9809-9824. doi:10.1021/ acscatal.1c02459

Nurttila, S. S., Brenner, W., Mosquera, J., van Vliet, K. M., Nitschke, J. R., and Reek, J. N. H. (2019). Size-Selective Hydroformylation by a Rhodium Catalyst Confined in a Supramolecular Cage. Chem. Eur. J. 25, 609-620. doi:10.1002/ chem. 201804333

Pullen, S., Tessarolo, J., and Clever, G. H. (2021). Increasing Structural and Functional Complexity in Self-Assembled Coordination Cages. Chem. Sci. 12, 7269-7293. doi:10.1039/d1sc01226f

Qi, X., Zhong, R., Chen, M., Sun, C., You, S., Gu, J., et al. (2021). Single MetalOrganic Cage Decorated with an Ir(III) Complex for $\mathrm{CO}_{2}$ Photoreduction. ACS Catal. 11, 7241-7248. doi:10.1021/acscatal.1c01974

Qiu, T., Gao, S., Liang, Z., Wang, D. G., Tabassum, H., Zhong, R., et al. (2021). Pristine Hollow Metal-Organic Frameworks: Design, Synthesis and Application. Angew. Chem. Int. Ed. 60, 17314-17336. doi:10.1002/ anie.202012699

Rayder, T. M., Bensalah, A. T., Li, B., Byers, J. A., and Tsung, C.-K. (2021). Engineering Second Sphere Interactions in a Host-Guest Multicomponent Catalyst System for the Hydrogenation of Carbon Dioxide to Methanol. J. Am. Chem. Soc. 143, 1630-1640. doi:10.1021/jacs.0c08957

Roland, S., Suarez, J. M., and M. Sollogoub, M. (2018). Confinement of Metal-NHeterocyclic Carbene Complexes to Control Reactivity in Catalytic Reactions. Chem. Eur. J. 24, 12464-12473. doi:10.1002/chem.201801278

Rooney, C. L., Wu, Y., Tao, Z., and Wang, H. (2021). Electrochemical Reductive N-Methylation with $\mathrm{CO}_{2}$ Enabled by a Molecular Catalyst. J. Am. Chem. Soc. 143, 19983-19991. doi:10.1021/jacs.1c10863

Shi, W., Quan, Y., Lan, G., Ni, K., Song, Y., Jiang, X., et al. (2021). Bifunctional Metal-Organic Layers for Tandem Catalytic Transformations Using Molecular Oxygen and Carbon Dioxide. J. Am. Chem. Soc. 143, 16718-16724. doi:10.1021/ jacs.1c07963

Shinde, S. S., Lee, C. H., Jung, J.-Y., Wagh, N. K., Kim, S.-H., Kim, D.-H., et al. (2019). Unveiling Dual-Linkage 3D Hexaiminobenzene Metal-Organic 
Frameworks towards Long-Lasting Advanced Reversible Zn-Air Batteries. Energy Environ. Sci. 12, 727-738. doi:10.1039/C8EE02679C

Shteinman, A. A. (2020). Bioinspired Oxidation of Methane: from Academic Models of Methane Monooxygenases to Direct Conversion of Methane to Methanol. Kinet Catal. 61, 339-359. doi:10.1134/S0023158420030180

Shteinman, A. A., and Mitra, M. (2021). Nonheme Mono- and Dinuclear Iron Complexes in Bio-Inspired C-H and C-C Bond Hydroxylation Reactions: Mechanistic Insight. Inorg. Chim. Acta 523, 120388. doi:10.1016/ j.ica.2021.120388

Wang, C.-P., Feng, Y., Sun, H., Wang, Y., Yin, J., Yao, Z., et al. (2021). SelfOptimized Metal-Organic Framework Electrocatalysts with Structural Stability and High Current Tolerance for Water Oxidation. ACS Catal. 11, 7132-7143. doi:10.1021/acscatal.1c01447

Wang, H., Jin, Y., Sun, N., Zhang, W., and Jiang, J. (2021). Post-synthetic Modification of Porous Organic Cages. Chem. Soc. Rev. 50, 8874-8886. doi:10.1039/d0cs01142h

Wang, K., Velmurugan, K., Li, B., and Hu, X.-Y. (2021). Artificial LightHarvesting Systems Based on Macrocycle-Assisted Supramolecular Assembly in Aqueous media. Chem. Commun. 57, 13641-13654. doi: $10.1039 / \mathrm{d} 1 \mathrm{cc} 06011 \mathrm{~b}$

Wang, W.-M., Wang, W.-T., Wang, M.-Y., Gu, A.-L., Hu, T.-D., Zhang, Y.-X., et al. (2021). A Porous Copper-Organic Framework Assembled by $\left[\mathrm{Cu}_{12}\right]$ Nanocages: Highly Efficient $\mathrm{CO}_{2}$ Capture and Chemical Fixation and Theoretical DFT Calculations. Inorg. Chem. 60, 9122-9131. doi:10.1021/ acs.inorgchem.1c01104

Yang, J., Li, K., Li, C., and Gu, J. (2021a). In Situ Coupling of Catalytic Centers into Artificial Substrate Mesochannels as Super-Active Metalloenzyme Mimics. Small 17 (35), 2101455. doi:10.1002/smll.202101455

Yang, J., Acharjya, A., Ye, M. Y., Rabeah, J., Li, S., Kochovski, Z., et al. (2021b). Protonated Imine-Linked Covalent Organic Frameworks for Photocatalytic Hydrogen Evolution. Angew. Chem. Int. Ed. 60, 19797-19803. doi:10.1002/ anie.202104870

Yi, J. D., Si, D. H., Xie, R., Yin, Q., Zhang, M. D., Wu, Q., et al. (2021). Conductive Two-Dimensional Phthalocyanine-based Metal-Organic Framework Nanosheets for Efficient Electroreduction of $\mathrm{CO}_{2}$. Angew. Chem. Int. Ed. 60, 17108-17114. doi:10.1002/anie.202104564

Yu, F., Jing, X., Wang, Y., Sun, M., and Duan, C. (2021). Hierarchically Porous Metal-Organic Framework/ $\mathrm{MoS}_{2}$ Interface for Selective Photocatalytic Conversion of $\mathrm{CO}_{2}$ with $\mathrm{H}_{2} \mathrm{O}$ into $\mathrm{CH}_{3} \mathrm{COOH}$. Angew. Chem. Int. Ed. 60, 24849-24853. doi:10.1002/anie.202108892

Yu, F., Poole, D., Mathew, S., Yan, N., Hessels, J., Orth, N., et al. (2018). Control over Electrochemical Water Oxidation Catalysis by Preorganization of
Molecular Ruthenium Catalysts in Self-Assembled Nanospheres. Angew. Chem. Int. Ed. 57, 11247-11251. doi:10.1002/anie.201805244

Yu, T., Li, Z., Lin, L., Chu, S., Su, Y., Song, W., et al. (2021). Highly Selective Oxidation of Methane into Methanol over Cu-Promoted Monomeric Fe/ZSM5. ACS Catal. 11, 6684-6691. doi:10.1021/acscatal.1c00905

Zeng, L., Cao, Y., Li, Z., Dai, Y., Wang, Y., An, B., et al. (2021). Multiple Cuprous Centers Supported on a Titanium-Based Metal-Organic Framework Catalyze $\mathrm{CO}_{2}$ Hydrogenation to Ethylene. ACS Catal. 11, 11696-11705. doi:10.1021/ acscatal.1c01939

Zhang, D., Martinez, A., and Dutasta, J.-P. (2017). Emergence of Hemicryptophanes: From Synthesis to Applications for Recognition, Molecular Machines, and Supramolecular Catalysis. Chem. Rev. 117, 4900-4942. doi:10.1021/acs.chemrev.6b00847

Zhang, H., Cheng, W., Luan, D., and Lou, X. W. (2021). Atomically Dispersed Reactive Centers for Electrocatalytic $\mathrm{CO}_{2}$ Reduction and Water Splitting. Angew. Chem. Int. Ed. 60, 13177-13196. doi:10.1002/anie.202014112

Zhang, Y., Li, J., and Kornienko, N. (2021). Towards Atomic Precision in HMF and Methane Oxidation Electrocatalysts. Chem. Commun. 57, 4230-4238. doi:10.1039/d1cc01155c

Zhou, Y., Liu, S., Gu, Y., Wen, G.-H., Ma, J., Zuo, J.-L., et al. (2021). In(III) MetalOrganic Framework Incorporated with Enzyme-Mimicking Nickel Bis(dithiolene) Ligand for Highly Selective $\mathrm{CO}_{2}$ Electroreduction. J. Am. Chem. Soc. 143, 14071-14076. doi:10.1021/jacs.1c06797

Zhou, Y., Wei, Y., Ren, J., and Qu, X. (2020). A Chiral Covalent Organic Frameworks (COFs) Nanozyme with Ultrahigh Enzymatic Activity. Mater. Horiz. 7, 3291-3297. doi:10.1039/D0MH01535K

Conflict of Interest: The author declares that the research was conducted in the absence of any commercial or financial relationships that could be construed as a potential conflict of interest.

Publisher's Note: All claims expressed in this article are solely those of the authors and do not necessarily represent those of their affiliated organizations, or those of the publisher, the editors, and the reviewers. Any product that may be evaluated in this article, or claim that may be made by its manufacturer, is not guaranteed or endorsed by the publisher.

Copyright (c) 2022 Shteinman. This is an open-access article distributed under the terms of the Creative Commons Attribution License (CC BY). The use, distribution or reproduction in other forums is permitted, provided the original author(s) and the copyright owner(s) are credited and that the original publication in this journal is cited, in accordance with accepted academic practice. No use, distribution or reproduction is permitted which does not comply with these terms. 